\title{
The Effect of the Sea Ice Freshwater Flux on Southern Ocean Temperatures in CCSM3: Deep Ocean Warming and Delayed Surface Warming
}

\author{
Clark H. Kirkman IV* \\ Department of Atmospheric Sciences, University of Washington, Seattle, WA \\ Cecilia M. Bitz \\ Department of Atmospheric Sciences, University of Washington, Seattle, WA
}

Submitted: October 13, 2009

Revised version submitted: September 8, 2010

* Corresponding author address: Clark Kirkman IV, Department of Atmospheric Sciences, University of Washington, Box 351640, Seattle, WA 98195-1640

email: ckirkman@washington.edu 


\section{Abstract}

We explore the role of sea ice freshwater and salt fluxes in modulating $21^{\text {st }}$ century surface warming in the Southern Ocean via analysis of sensitivity experiments in the Community Climate System Model version 3 (CCSM3). In particular, we investigate whether a change in these fluxes can cause surface cooling in the Southern Ocean, expand sea ice, and increase deep oceanic storage of heat. Our results indicate that in response to the doubling of $\mathrm{CO}_{2}$ concentrations in the atmosphere in CCSM3, net freshwater input from sea ice to the ocean increases south of $58^{\circ} \mathrm{S}$ (owing to less growth) and decreases from $48-58^{\circ} \mathrm{S}$ (owing to less melt). The freshwater source from changing precipitation in the model is considerably less than from sea ice south of $58^{\circ} \mathrm{S}$, but serves to compensate for the reduction in sea ice melt near the ice edge, leaving almost no net freshwater flux change between about $48-58^{\circ} \mathrm{S}$. As a result, freshwater input principally from sea ice reduces ocean convection, which in turns reduces entrainment of heat into the mixed layer and reduces upward heat transport along isopycnals below about $1000 \mathrm{~m}$. The reduced upward heat transport (from all sources) causes deep ocean heating south of $60^{\circ} \mathrm{S}$ and below $500 \mathrm{~m}$ depth, with a corresponding surface cooling in large parts of the Southern Ocean in the model. These results indicate that changing sea ice freshwater and salt fluxes are a major component of the $21^{\text {st }}$ century delay in surface warming of the Southern Ocean and weak reduction in Antarctic sea ice in model projections. 


\section{Introduction}

Earth's surface is expected to warm significantly during the $21^{\text {st }}$ century due to increasing greenhouse gas concentrations in the atmosphere from anthropogenic sources. The globally averaged surface atmospheric warming is likely to be in the range of $2.4-6.4^{\circ} \mathrm{C}$ by year 2100 (IPCC 2007), and large variations in regional warming patterns are expected. One much studied cause of departure from the global mean in high northern latitudes is known as polar amplification. The primary mechanism is usually thought to be a positive feedback between surface temperature and planetary albedo: an increase in temperature causes highly reflective (land or sea) ice to melt, reducing the amount of solar radiation reflected to space, which in turn increases the temperature. This feedback has been shown to amplify the future temperature response in climate models by about a factor of 2 in the Arctic, where sea ice and snow on land are prevalent in the modern climate (Hall 2004).

Despite the presence of sea ice, polar amplification is not generally observed at the surface of the Southern Ocean in $21^{\text {st }}$ century scenarios. In fact, some future climate runs show a statistically significant decrease in temperature in the Ross Sea zone of the Southern Ocean (e.g., Bitz et al. 2006). This is not just a phenomenon of future climate change; in the past few decades, SATs in some parts of the Southern Ocean have experienced no significant increase and sea ice coverage has expanded (Chapman and Walsh 2007; Cavalieri and Parkinson 2008; Steig et al. 2009). In addition, the average SAT of the Southern Hemisphere has only warmed at about half the rate of the Northern Hemisphere (IPCC 2007).

Given that most of the primary anthropogenic greenhouse gases driving future climate change are well mixed throughout the atmosphere, there is no obvious longwave radiative 
forcing difference in this region to account for the lack of a strong surface warming trend. Though ozone $\left(\mathrm{O}_{3}\right)$ is a greenhouse gas, it largely impacts temperatures in the stratosphere via ultraviolet radiation absorption. The seasonal loss of ozone in the high southern latitudes creates anomalous temperature gradients in the stratosphere, strengthening the polar vortex in the Southern Hemisphere. These wind anomalies propagate down to the surface (Thompson et al. 2005) and have been argued as one mechanism driving anomalous air-sea heat exchange (Russell et al. 2006).

Recent data indicate that while the surface is warming less than elsewhere, warming below the surface is relatively high in the Southern Ocean (Gille 2002; Johnson et al. 2008). It has been estimated that continued mid depth and deeper warming in the Southern Ocean (south of $30^{\circ} \mathrm{S}$ ) could be responsible for roughly half of the global ocean heat uptake below the mixed layer during the $21^{\text {st }}$ century (Gregory 2000). This sets the Southern Ocean apart from the rest of the world's oceans, which are expected to continue warming primarily near the surface.

Widespread and deep mixing distinguishes the Southern Ocean and plays an important role in modulating the rate and degree of atmospheric warming seen in the future. By accumulating heat at depth, Southern Ocean heat storage offers a means of longer-term storage relative to the upper ocean heat uptake seen in most of the rest of the oceans.

Despite the importance of the Southern Ocean, measurements are relatively sparse and different climate models yield very different surface warming signatures in future climate projections (figure 1). The Southern Ocean is not the only region that is highly uncertain; intermodel variability of the Arctic surface warming is even higher. However, given the size of the Southern Ocean and the relatively small magnitude of the (surface) temperature change seen in 
these model integrations, it is the region of largest uncertainty relative to the local warming (figure 2). Thus, the Southern Ocean is likely one of the least understood critical components of the climate system.

Several hypotheses regarding the mechanisms of this warming have been discussed in the literature, though the exact cause(s) are not fully understood. One possibility is that Southern Ocean heat uptake is driven by a unique sensitivity to increasing greenhouse gas concentrations. Gregory (2000) ran and analyzed an ensemble of four idealized $\mathrm{CO}_{2}$ ramping experiments in the Hadley Climate Model (HADCM2) in order to determine which ocean heat transport processes were important in determining transient climate change. The results of this ensemble showed a warming of the Southern Ocean from beneath the mixed layer down to around 2000m depth. Analysis indicated that a reduction of upward isopycnal diffusion was the prime ocean mechanism for the retention of heat below the mixed layer in the Southern Ocean. There was also a reduction of heat loss from the surface ocean to the atmosphere, which led Gregory to develop the following hypothesis of the transient deep Southern Ocean warming: A reduction of surface heat loss to the atmosphere reduced convection, which in turn increased the subsurface temperature. This decreased the isopycnal temperature gradient, which reduced upward isopycnal diffusion, and consequently warmed the deeper ocean. Results from Dalan et al. (2005) support the role of decreasing upward isopycnal mixing and diffusion as the prime ocean mechanism leading to deep Southern Ocean warming.

Huang et al. (2003) ran a $1 \%$ per year $\mathrm{CO}_{2}$ ramping experiment in the Massachusetts Institute of Technology Ocean General Circulation Model with a simplified ocean basin. Using an adjoint of this model, Huang et al. also found that isopycnal mixing was the most important 
contributor to Southern Ocean heat uptake. In further agreement with Gregory's hypothesis, the deep heat uptake was more sensitive to the surface heat flux than the surface freshwater flux. This is in spite of the fact that in their study, freshwater fluxes (Precipitation + RunoffEvaporation) and surface heat fluxes were found to contribute equally to the surface buoyancy forcing in the Southern Ocean.

Increasing wind stress on the Southern Ocean has also been discussed as a possible mechanism for deep ocean heat uptake (Russell et al. 2006; Fyfe et al. 2007). This increased stress is due to a poleward-intensifying atmospheric jet stream that is enhanced largely by stratospheric ozone depletion and rising greenhouse gas concentrations. (Sexton 2001; Thompson and Solomon 2002; Arblaster and Meehl 2006). Increased wind stress enhances mixing under the jet that, in combination with surface warming, results in an anomalous downward flux of heat. This mechanism is not at odds with Gregory's, as it occurs much further north (see, e.g., Fyfe et al. 2007) and extends only to intermediate depths.

The role of freshwater forcing, particularly that from sea ice, in the delayed surface warming and heat uptake in the Southern Ocean was explored in Bitz et al. (2006) in the Community Climate System Model version 3 (CCSM3). Their results indicate that changes in sea ice alone can account for much of the deep Southern Ocean heat uptake in a $\mathrm{CO}_{2}$ doubled climate. Following Gregory's hypothesis and noting that surface density changes south of the Drake Passage (where most of the warming occurred in CCSM3) were due to changes in salinity, not temperature, it was concluded that sea ice induced salinity changes were responsible for the deep ocean heat uptake. This result is not necessarily in contradiction to those of Huang et al., who did not include sea ice in their analysis of the role of freshwater forcing. In addition, 
CCSM3 has a more realistic sea ice model that may better simulate the sea ice response to forcings. It is important to note that the experimental design of Bitz et al. (2006) implicates sea ice melt in deep Southern Ocean warming, but does not allow for the understanding of which sea ice processes are responsible for the observed changes. As described below, the goal of the present study is to analyze the effect of changes in the freshwater exchange between sea ice and the ocean.

Aiken and England (2008) explored the role of freshwater forcing through the analysis of several experiments that mimicked the loss of Antarctic sea ice in different ways. They ran the University of Victoria intermediate complexity Earth System Climate Model, perturbed with a spatially uniform freshwater forcing equivalent to melting the climatological Antarctic sea ice volume. When distributed over the entire sea ice covered region of the Southern Ocean over a 100 year period (i.e., only a few centimeters of freshwater added each year), the response was only a slight warming at depth in the Antarctic Bottom Water (AABW) overturning circulation and a cooling of Antarctic Intermediate Waters (AAIW) in the midlatitudes (this is in qualitative agreement with the results of this paper). The strength of the AABW circulation and Antarctic Circumpolar Current (ACC) was weakened during the first 70 years. Adding meltwater over a shorter period of time and/or only near the continental margin had little additional effect on the Southern Ocean circulation, though recovery from the forcings was somewhat faster.

Freshwater changes from precipitation have also been considered as a cause of sea surface temperature (SST) change in the Southern Ocean. Liu and Curry (2010) find that recent warming in the Southern Hemisphere drove an increase in the precipitation (mostly snow) in the Southern Ocean in both observations and global climate models. They argue that this freshwater 
source had a stabilizing effect on the Southern Ocean in two ways: 1) reducing the upward ocean heat flux to the sea ice by reducing convection and 2) by increasing the albedo of the sea ice cover, reflecting more solar shortwave radiation. They posit that this mechanism caused SSTs to be colder in the marginal ice zone and sea ice to expand in the last half of the $20^{\text {th }}$ century. Further, they claim that $21^{\text {st }}$ century Antarctic sea ice loss in CCSM3 is driven by 1) increased atmospheric heat transport southward and 2) increased rainfall on the ice that drives anomalous melting and allows greater solar shortwave radiation absorption by the ocean. However, they do not compare their proposed precipitation mechanisms to the sea ice freshwater flux and associated mechanisms discussed by Bitz et al (2006) and Aiken and England (2008).

The conclusion of Gregory (2000) that reduced convection in the Southern Ocean could lead to a reduced upward isopycnal mixing of heat toward the surface is substantially confirmed by more recent studies. His proposed mechanism is centered on anomalous surface buoyancy initiating a chain of events that lead to deep warming. An anomalous buoyancy forcing would first inhibit convection, cause heat to accumulate a the base of the mixed layer, reduce the (vertical) isopycnal temperature gradient, and finally cause the accumulation of heat at depth due to a reduced isopycnal mixing efficiency. However, Gregory was uncertain what initiated the process by weakening the convection. Studies remain less conclusive on this matter. The goal of the present paper is to explore the anthropogenic influence on surface fluxes, buoyancy, convection, and ultimately the deep Southern Ocean warming in the $21^{\text {st }}$ century. This is accomplished through the comparison of 21 st century sensitivity experiments in CCSM3 (described in the next section), including an analysis of the role of freshwater forcing from sea ice and precipitation. Sea ice has numerous properties that influence the ocean and make it an 
interesting component of the climate to study with regards to deep Southern Ocean heat uptake. It has a high albedo, which allows it to cool the ocean in summer by reflecting solar radiation, insulates the ocean by reducing sensible and latent heat fluxes to the atmosphere, and rejects salt when it grows in winter and releases freshwater during the melting season. Our results show that the net freshwater flux from sea ice (freshwater plus brine, henceforth called the sea ice FW flux) is critical. This might be expected because unlike much of the global ocean surface, the density of the Southern Ocean is more sensitive to changes in salinity than temperature. This is particularly true south of the ACC (figure 3), where the deepest warming in CCSM3 reported by Bitz et al. occurred. 


\section{Model Information and Experimental Design}

The model we used to investigate the Southern Ocean warming delay is version 3 of the

Community Climate System Model (CCSM3; Collins et al. 2006). The polar climate of the $20^{\text {th }}$ and $21^{\text {st }}$ centuries in this model is discussed in Meehl et al. (2006) and Holland et al. (2006).

CCSM3 is a global coupled atmosphere, ocean, sea ice, and land model. The integrations we analyzed have an atmosphere component with spectral triangular truncation at wavenumber 42 (T42), which is roughly equivalent to $2.8 \mathrm{deg}$ in the horizontal (for land as well). The atmosphere has 26 vertical levels. The ocean and sea ice have zonal resolution of $1.125 \mathrm{deg}$ and the meridional resolution of $0.54 \mathrm{deg}$, except in the subtropics and tropics where the resolution is finer. The ocean model in CCSM3, the Parallel Ocean Program (POP), is a constant mass ocean, so the addition and removal of water from the ocean (through precipitation, evaporation, and sea ice growth/decay) is mimicked by modifying the ocean salt content. The Gent-McWilliams mixing scheme is used to parameterize mesoscale eddies in the ocean (Gent and McWilliams 1990).

The $20^{\text {th }}$ century Southern Ocean sea ice cover in CCSM3 tends to be more extensive than indicated by observations (Holland and Raphael 2006). This is true in all sectors and all times of year, though particularly so in winter and spring. Variability of the sea ice cover is also greater than observed, though its spatial structure corresponds reasonably well. The degree to which CCSM3 represents real-world convection in the Southern Ocean has been assessed by comparison of model CFC-11 ocean penetration to World Ocean Circulation (WOCE) data (Gent et al. 2006). Though the large scale patterns of deep convection appear to be captured, Gent et al. noted that CFC-11 concentrations were too high at depth in the west Pacific sector $\left(170^{\circ} \mathrm{E}\right.$, 
implying overly vigorous deep convection. Deep convection along $0^{\circ} \mathrm{E}$ was lower (low CFC-11 concentrations) and shifted further north than observations, but it was noted that there was better agreement to the north of the Weddell Sea.

Three model runs are compared in this paper in order to assess the role of the sea ice FW flux on the Southern Ocean warming delay: a control run, a warming run, and a sensitivity run. The control run has periodic forcing only from a 1990s climatology and will be simply referred to as 'control'. The warming run branches from the 1990 s control and increases atmospheric $\mathrm{CO}_{2}$ by $1 \%$ per year and will be referred to as 'co2ramp'. The sensitivity experiment examined is a modified version of co2ramp. It was changed so that the ocean model was given climatological FW fluxes from sea ice melting (or a negative flux if from brine rejection) derived from the 1990s control instead of the computed values, thereby eliminating feedbacks between climate change and sea ice FW exchange while ramping $\mathrm{CO}_{2}$. Precipitation, evaporation, and runoff were unaltered. Thus, comparison to co2ramp highlights the effect of the change in the freshwater exchange of sea ice and ocean in the climate system. We will refer to this sensitivity experiment as 'climoFW'. 


\section{Results}

We begin with an analysis of the idealized $\mathrm{CO}_{2}$ ramping experiment (co2ramp) to identify the patterns of heat uptake that the Southern Ocean experiences in CCSM3. In addition, we will explore the concomitant surface buoyancy forcings of this experiment relative to the 1990s. We will follow this analysis with results from the idealized $\mathrm{CO}_{2}$ ramping experiment with climatological sea ice FW flux (climoFW) in order to determine what parts of the co2ramp changes can be explained by the changing sea ice FW flux.

a) Effects of $\mathrm{CO}_{2}$ doubling

In response to the increase in $\mathrm{CO}_{2}$ in the atmosphere, SATs increase across most of the global ocean (figure 4). The top panel also depicts the Southern Ocean warming delay, where the magnitude of SAT change from the 1990s climate is less than $+/-0.5 \mathrm{~K}$. This is in sharp contrast to the Arctic Ocean, which, along with the North Pacific Ocean, has the strongest warming signal anywhere. Such hemispherical asymmetries are popular topics and are clearly seen in $21^{\text {st }}$ century projections.

Since one of the goals of this paper is to determine if $\mathrm{CO}_{2}$ driven changes in the sea iceocean freshwater exchange can sufficiently alter convection and fit into Gregory's hypothesis of Southern Ocean heat uptake, we focus first on how the change in the sea ice FW flux affects convection. For this, we examine the difference in surface density due to $\mathrm{CO}_{2}$ doubling (and later, due to the change in the sea ice FW flux). As stated before, the density of the water in the Southern Ocean is generally more sensitive to changes in salinity than temperature. Figure 5 
(top panel) illustrates the surface density change due to both salinity and temperature effects between co2ramp and the control. It is clear that the surface temperature change due to $\mathrm{CO}_{2}$ doubling is unable to rival the effect of its associated salinity changes south of approximately $58^{\circ} \mathrm{S}$.

Figure 6 helps clarify what processes are contributing to these surface density differences by decomposing the surface density flux (as per Speer and Tziperman 1992) into heat, precipitation, evaporation, runoff, and sea ice FW flux effects. It indicates that the surface density anomaly between co2ramp and control can largely be attributed to changes in the sea ice FW flux. The latitudinal dependence of the sea ice FW influence can be understood by considering how sea ice grows and is advected in the Southern Ocean. Sea ice in this region tends to grow in polynyas along the Antarctic coast and is advected away from the continent by currents and wind (though CCSM3 cannot resolve polynyas, sea ice divergence away from the coast drives very high sea ice growth rates near the continent). Exposed to anomalous downward longwave radiative forcing (as in co2ramp relative to the control), this equatorward moving sea ice will melt sooner, or farther south, than in the control climate. This would result in a decrease in sea ice meltwater input to the surface ocean in the marginal sea ice regions and an increase to the south. This is the sea ice FW flux pattern seen in figure 6. Changes in precipitation minus evaporation (P-E) also act to reduce density in the co2ramp Southern Ocean, but to a lesser degree than sea ice south of about $61^{\circ} \mathrm{S}$. Of the anomalous freshwater driven density changes near $64^{\circ} \mathrm{S}$, where the density flux due to all freshwater sources is at its maximum, about $70 \%$ is from sea ice FW flux changes and about $30 \%$ is from P-E changes. To the north, between 48 $58^{\circ} \mathrm{S}$, the effect of changes in P-E on surface density largely cancels those from sea ice, leading 
to virtually no net freshwater driven density flux in these latitudes. Thus, the overall pattern of density change due to salinity most closely resembles the increased freshening from sea ice south of about $58^{\circ} \mathrm{S}$. Increases in precipitation in co2ramp relative to the control are likely due to the higher surface temperatures and Clausius-Clapeyron effect (e.g., see Soden and Held 2006). Increased runoff from Antarctica in co2ramp has a negligible effect on density.

The response of the deep Southern Ocean temperatures to $\mathrm{CO}_{2}$ forcing in co2ramp is depicted in figure 7 (top panel). Warming appears to occur in two separate regions: south of the ACC and near $45^{\circ} \mathrm{S}$. The first region of warming extends down to about $3 \mathrm{~km}$ with a maximum warming of over $0.6 \mathrm{~K}$. The second region extends from the surface down to about $1 \mathrm{~km}$ and has a warming pattern that is warmest at the surface $(>1 \mathrm{~K})$ and decays with depth. The small region of cooling near the surface of the far south Southern Ocean is in qualitative agreement with the relatively cool SATs shown in figure 4.

The spatial distribution of the warming can be seen at two depths in figure 8 . The upper left panel shows that warming in co2ramp at about 600m depth near Antarctica takes place in three relatively distinct regions: in and near the Weddell, Ross, and Davis Seas. This warming signal is mixed relatively evenly south of the ACC at about 2,100m depth (figure 8, bottom left panel). Figure 9 (top panel) shows the depth integrated heat content change in the Southern Ocean.

Figure 10 indicates that the heating rate south of the ACC is seasonally variable, both in the control climate and in co2ramp. In fact, the largest changes due to $\mathrm{CO}_{2}$ doubling in this seasonal heating rate occur during the typical cooling season, roughly August through November. These four months account for $60 \%$ of the anomalous heat uptake relative to the 
control, and the sign of the heating rate changes from cooling to warming. This implies that for deep Southern Ocean warming, a reduction of heat outflow from Aug.-Nov. is more (though not solely) important than an increase in heat inflow from Dec.-Jul. during transient climate change. Thus, understanding processes that could modulate this outflow of heat, such as sea ice FW flux driven convective changes, are critical. Indeed, figure 11 indicates that heat transport changes by vertical eddy mixing (including convection) across $1000 \mathrm{~m}$ depth is the prime contributor to heating below $1000 \mathrm{~m}$ depth from $55-65^{\circ} \mathrm{S}$. Changes in the meridional eddy heat flux below $1,000 \mathrm{~m}$ depth are of modest importance south of $60^{\circ} \mathrm{S}$ and of opposite sign to the vertical eddy heat flux change. The heat transport changes by the mean temperature and the mean flow (both vertically and horizontally as for eddies) below 1,000m depth are unable to account for heating in the vicinity of $55-65^{\circ} \mathrm{S}$. However, they may be more important south of this region due to the compensating heat transports by vertical and horizontal eddy mixing and small, same signed mean transports from $65-70^{\circ} \mathrm{S}$.

The top panel of figure 12 shows the ideal age signature of the co2ramp experiment. Ideal age is a passive tracer in the Parallel Ocean Program (POP) ocean model in CCSM3 that is intended to model the length of time a parcel of water has been away from the surface of the ocean, much like oxygen concentrations in real ocean water. Water is older throughout most of the ocean south of about $50^{\circ} \mathrm{S}$, from near the base of the mixed layer down to the ocean floor. Figure 13 diagrams the spatial distribution of the change in ideal age. The three modes of warming appear here as three modes of aging at $579 \mathrm{~m}$ depth. This change in age could be due to either a decreased input of young water (deep convection), an increased input of older water, or both. Since there is no evident dipole in ideal age indicating a redistribution of older water, it 
is likely that a substantial fraction of the change is due to a reduction in deep convection. This also means that a simple vertical shift in the depth of the Atlantic Meridional Overturning Circulation (AMOC) is not responsible for the age or temperature patterns. Had the change in ideal age from control to co2ramp been due to a slowdown in the AMOC, the entire path it follows from the North Atlantic to the Southern Ocean should show a positive aging signal. This is not the case (not shown). Most importantly, though, the large ideal age changes are below the level at which North Atlantic Deep Water (NADW) and Circumpolar Deep Water (CDW) circulate. Isopycnal mixing, however, cannot be ruled out as a contributing factor to these heat and age patterns. Given that the rest of the results presented here are not inconsistent with Gregory's hypothesis, it is possible that reduced vertical isopycnal mixing and reduced deep convection both explain the change in temperature and ideal age from the control to co2ramp.

\section{b) climoFW results}

Here we discuss the results of the climoFW experiment. The difference between co2ramp and climoFW is the response to changes in the sea ice FW flux that result from doubling $\mathrm{CO}_{2}$. Since the $\mathrm{CO}_{2}$ radiative forcing is the same in both experiments, their difference can be thought of as a type of hosing experiment where freshwater is added in some locations and removed in others (with no net change) depending on the sea ice response of co2ramp relative to the control.

Figure 4 (bottom panel) shows that the climoFW experiment southern hemisphere SATs are warmer than the co2ramp run, particularly in the Southern Ocean. This difference indicates 
that the deep ocean heat uptake in the Southern Ocean in climoFW is reduced relative to co2ramp. The effect of the warmer climoFW surface temperatures on ocean surface density can be seen in figure 5 (bottom panel). Temperature differences act to stabilize the climoFW surface relative to co2ramp throughout the Southern Ocean. The relative effect of the salinity differences on density is roughly antisymmetric about $58^{\circ} \mathrm{S}$, with salinity acting to reduce (increase) density in co2ramp south (north) of about $58^{\circ} \mathrm{S}$. This is equivalent to climoFW being saltier to the south and fresher to the north.

Figure 7 (bottom panel) shows the ocean warming that can be accounted for by the change in the sea ice FW flux from the 1990s climate to the co2ramp climate. The warming patterns of the two panels of figure 7 near Antarctica are strikingly similar. Their northward extents, minimum depth (around $250 \mathrm{~m}$ ), and penetration to deep waters are comparable. The magnitudes of warming are also similar throughout much of the warmed region, with the notable exception of the warming maximum from about $300-750 \mathrm{~m}$. Thus, it appears that the change in the sea ice FW flux to the Southern Ocean in a warming world is a major contributor to deep ocean heat uptake. Another notable difference between the two plots is that the change in sea ice FW flux does nothing to explain the shallower warming near $45^{\circ} \mathrm{S}$. In fact, holding the sea ice FW flux to the 1990s climatology enhances the warming at these latitudes. This is a direct result of the maintenance of deep ocean venting to the surface in climoFW. These results are consistent with figure 6 , which identified the change in the sea ice FW flux south of about $61^{\circ} \mathrm{S}$ between the control and co2ramp as inducing the greatest buoyancy forcing in the region of deepest warming.

Figure 8 (right panels) shows the spatial patterns of warming attributable to the changing 
sea ice FW flux at two depths in the ocean. Comparison of climoFW to co2ramp yields very similarly shaped regions and magnitudes of warming, especially near Antarctica. The patterns of warming explained by the change in the sea ice FW flux are most alike at $2125 \mathrm{~m}$, due in part to the fact that surface warming from the greenhouse gas warmed atmosphere cannot penetrate this deep outside of the Southern Ocean in 80 years (bottom panels). The region of warmer temperatures in climoFW near $45^{\circ} \mathrm{S}$ is visible in the upper-right plot of figure 8 (in blue) and appears to be spatially co-located with the warmer SATs seen in figure 4. Figure 9 (bottom panel) shows the depth integrated change of heat attributable to the change in the sea ice FW flux. Within the climatological maximum 15\% sea ice contour, it appears that the change in the sea ice FW flux well explains the amount of heat uptake (top panel). It slightly overestimates the heating in the Weddell Sea region and underestimates heating to the west of the Antarctic Peninsula.

The ideal age signature of climoFW (figure 12, bottom panel) indicates that the sea ice FW flux is heavily involved with the processes feeding the deepest mode of warming. However, it is apparent that holding the sea ice FW flux to the 1990s climatology has a very strong effect on ideal age, even overshooting the age difference between co2ramp and the control. This demonstrates the degree of influence the sea ice FW flux has in the deep Southern Ocean. Moreover, the pattern of age difference is a very good match. The overshoot in the reduction of ideal age relative in climoFW relative to co2ramp is largely in the Weddell Sea region (figure 13, right panels). Water in a small region along the Antarctic coast south of the Cape of Good Hope at $579 \mathrm{~m}$ depth is younger in co2ramp. This is probably due to increased convection locally. The temperature in this location (figure 8) also appears to have decreased, which would support 
this assertion by implying a relatively greater venting of heat to the atmosphere. It is important to note the similarity in the zonal mean structure and spatial distribution of temperature anomalies and ideal age changes. It is likely that both are responding to the same mechanism.

These results indicate that a reduction in deep convection is likely playing a role in the deep Southern Ocean warming. Figure 14 shows which water masses (densities) are changing in volume in co2ramp and climoFW. Relative to the control, both climoFW and co2ramp have less of the densest water $(\sigma>27.5)$ at the surface. Relative to each other, co2ramp has a greater loss of this very dense water than climoFW and has a larger volume of less dense water with $\sigma=27$ 27.5. This indicates that a warming Earth would likely have reduced AABW formation in the Southern Ocean and that much of this reduction could be accounted for by the change in the sea ice FW flux between the sea ice and the ocean. Water mass volume change rates in figure 14 were calculated by dividing the difference in water volume at each density between two experiments by the time frame over which the differences were created (the average of years 6079 , or 69.5 years):

$$
\operatorname{rate}(\sigma)=\frac{1}{69.5} *\left(V_{\text {co2 } \operatorname{ramp}}(\sigma)-V_{\text {control }}(\sigma)\right)
$$

where $V_{\text {co2ramp }}(\sigma)$ and $V_{\text {control }}(\sigma)$ are the mean volume of water as a function of density $(\sigma)$ in the co2ramp and control experiments in years $60-79$, respectively. The calculation was performed with a bottom depth of $104 \mathrm{~m}$ to roughly approximate the depth of the mixed layer and ice shelf sill depth. Though CCSM3 does not have ice shelves and its deep water formation is not perfect, this depth provides for a reasonable diagnostic of how Southern Ocean water masses important to $\mathrm{AABW}$ formation are partitioned in these model experiments. 
Comparison of the co2ramp and climoFW experiments shows that most of the pattern and magnitude of deep Southern Ocean warming in the co2ramp experiment can be explained by the changing sea ice FW flux. North of the climatological maximum $15 \%$ sea ice extent, the changing sea ice FW flux is unable to explain oceanic warming. In fact, as the climoFW experiment indicates, holding the sea ice FW flux constant in $\mathrm{CO}_{2}$ ramping experiment turns off the deep ocean heat uptake, warms the Southern Hemisphere midlatitudes, and overheats the midlatitude Southern Ocean relative to co2ramp. The surface density changes from the control to co2ramp in the Southern Ocean are largely due to a decrease in sea ice export south of the Drake Passage, freshening to the south and densifying to the north. Net precipitation changes also tended to freshen the ocean from about $48-65^{\circ} \mathrm{S}$, offsetting the decreased ice export buoyancy forcing. However, the climoFW experiment clearly indicates that it is not necessary to invoke anomalous precipitation induced buoyancy forcing as an initiating mechanism to explain the spatial structure or magnitude of (relative) surface cooling and deep warming in the Southern Ocean. Changes to P-E could have a role as a feedback to changes in the sea ice FW flux, though, as P-E decreases in co2ramp compared to climoFW between about $52-75^{\circ} \mathrm{S}$ (not shown). This negative feedback on surface density (increased sea ice FW flux to the ocean causing less net precipitation in the sea ice zone), is part of the coupled response in co2ramp. 


\section{Discussion}

Results from the climoFW experiment indicate that the magnitude and spatial pattern of the deepest Southern Ocean heat uptake mode, delayed surface warming, and weak sea ice retreat are well explained by changes in the sea ice FW flux. We have also shown that the surface of the Southern Ocean is freshened south of about $55^{\circ} \mathrm{S}$ in a $\mathrm{CO}_{2}$ enhanced climate. This freshening is mainly due to a decrease in northward sea ice export that increases melting to the south. Surface heat fluxes and precipitation have only a minor effect on the surface density in this region. Ideal age results are consistent with a reduced sea ice FW flux, and indicate an aging of deep Southern Ocean waters in a warming world. This could imply reduced deep convection and/or reduced isopycnal mixing of water and heat upward.

Combining these model results with those of the authors mentioned in the introduction of this paper, we have an expanded view of deep Southern Ocean warming. A reduction in sea ice export from near Antarctica acts to freshen the surface ocean. Being more sensitive to changes in salinity than temperature in this region, the convection of this water is reduced. Heat is accumulated at the base of the mixed layer since it can not vent to the surface and atmosphere as efficiently. This in turn reduces the isopycnal temperature gradient and slows the mixing of heat out of the deep Southern Ocean, increasing its temperature. This is consistent with Gregory's hypothesis, and helps integrate the results of Bitz et al. (2006) with prior literature. It is worth mentioning again that the discrepancy between the 'freshwater forcing' and 'heat forcing' papers in the literature could just be a matter of differences in how the freshwater forcing is defined (including sea ice or not) and sea ice model differences. Both explanations could just be parts of the same puzzle rather than two versions of the same piece. Further reconciling the differences 
of these two views by unifying the language used as well as determining whether there are any important interactions between the sea ice FW flux and applicable surface heat fluxes would be a constructive next step. It is also worth noting again that precipitation induced freshening is not a necessary initiating mechanism of cooling the surface (or warming the deep layers) of the Southern Ocean in CCSM3, since the magnitude and structure of temperature change is captured quite well by the anomalous sea ice FW flux.

Though changes in the sea ice FW flux were able to explain much of the deepest mode of deep Southern Ocean heat uptake, it was unable to account for the midlatitude mode we reported. In fact, the climoFW experiment experienced additional warming beyond the co2ramp experiment due to continued venting of the deep ocean. This implies that, at least in CCSM3, there is at least one additional important mechanism at play that reduces the net subduction of heat in the midlatitudes. This further implies a possible compatibility of this paper's results with prior results indicating the importance of surface heat fluxes. Surface heating could act to increase stratification in downwelling regions, particularly since the density of the midlatitude Southern Ocean is significantly more sensitive to temperature than south of the ACC. In addition, since this region is near the latitude of the atmospheric jet stream, it makes sense that if anomalous wind stress is responsible for at least part of the subsurface ocean heat uptake (or midlatitude venting), it would be most pronounced here. The results of this paper are relatively free of influence by anomalous wind stress, as indicated in figure 15. Changes in peak to peak wind stress between the control and co2ramp are less than $5 \%$ by the end of the experiments, which is relatively small by comparison to other wind forced experiments (e.g., Fyfe et al. 2007).

We have only investigated the response to $\mathrm{CO}_{2}$ forcing in this paper. The midlatitude 
mode of warming is even higher in integrations of CCSM3 that include anthropogenic changes to stratospheric ozone. However, we do not expect the response to ozone to play a role in the deep Southern Ocean heat uptake in CCSM3. This speculation is based on the results of Fyfe et al. (2007) who showed that anthropogenic $\mathrm{CO}_{2}$ and ozone forced changes in winds explained warming only in southern midlatitudes. Our results in figure 7 (lower panel) indicate that changes in the sea ice FW flux dampen the wind-forced midlatitude mode somewhat. This is likely due to the anomalous storage of heat at depth removing a potential heat source to the midlatitudes. 


\section{Conclusions}

We have shown that the freshwater exchange between sea ice and the ocean has a substantial influence on deep ocean heat uptake in the Southern Ocean in CCSM3. The mean response to increasing atmospheric greenhouse gas concentrations is a reduction in sea ice growth near Antarctica and reduced equatorward sea ice volume transport. These changes result in a loss of brine rejection south of about $58^{\circ} \mathrm{S}$ and a loss of sea ice melt water between about 48 and $58^{\circ} \mathrm{S}$. Precipitation adds a small amount to the anomalous freshwater input from sea ice south of $58^{\circ} \mathrm{S}$ and offsets the reduction of sea ice melt between about $48-58^{\circ} \mathrm{S}$, resulting in virtually no net freshwater input to this region. The freshwater flux changes reduce ocean convection south of about $60^{\circ} \mathrm{S}$, including the formation of AABW. The reduction in ocean convection due primarily to less sea ice growth then likely initiates a reduction in upward isopycnal heat transport as described by Gregory (2000), enhancing deep ocean heat uptake. Changes in the sea ice-ocean freshwater exchange are a critical component of this uptake in CCSM3 at a depth that effectively sequesters heat from the atmosphere, delaying warming both locally in the Southern Ocean and globally.

Acknowledgements. We thank Marika Holland for offering data from her sensitivity experiment with prescribed climatological sea ice freshwater flux to the ocean. We thank Joellen Russell, Ilana Wainer, and Gokhan Danabasoglu for helpful conversations about modeling Southern Ocean dynamics. We thank David Battisti and Igor Kamenkovich for their assistance while serving on the committee for the Master's thesis this article grew out of. We also thank three anonymous reviewers for valuable comments on this article. This research was supported by the 
Department of Energy Climate Change and Prediction Program grant number 0013706. 


\section{References}

Aiken, C.M., England, M.H., 2008, Sensitivity of the Present-Day Climate to Freshwater Forcing Associated with Antarctic Sea Ice Loss, J. Climate, 21, 3936-3946.

Arblaster, J.M., Meehl, G.A., 2006, Contributions of External Forcings to Southern Annular Mode Trends, J. Climate, 19, 2896-2905.

Bitz, C.M., Gent, P.R., Woodgate, R.A., Holland, M.M., Lindsay, R., 2006, The Influence of Sea Ice on Ocean Heat Uptake in Response to Increasing CO2, J. Climate, 19, 2437-2450.

Chapman, W. L., and J. E. Walsh, 2007, A Synthesis of Antarctic Temperatures, Journal of Climate, 20(16), 4096-4117, doi:10.1175/JCLI4236.1.

Cavalieri, D. J., and C. L. Parkinson, 2008, Antarctic sea ice variability and trends, 1979-2006, Journal of Geophysical Research, 113 (C7), 1-19, doi:10.1029/2007JC004564.

Collins, W.D., and Coauthors, 2006, The Community Climate System Model Version 3 (CCSM3), J. Climate, 19, 2122-2143.

Dalan, F., Stone, P.H., Sokolov, A.P., 2005, Sensitivity of the Ocean's Climate to Diapycnal 
Diffusivity in an EMIC. Part II: Global Warming Scenario, J. Climate, 18, 2482-2496.

Fyfe, J. C., 2006, Southern Ocean warming due to human influence, Geophys. Res. Lett., 33, L19701, doi:10.1029/2006GL027247.

Fyfe, J.C., Saenko, O.A., Zickfeld, K., Eby, M., Weaver, A.J., 2007, The Role of Poleward Intensifying Winds on Southern Ocean Warming, J. Climate, 20, 5391-5400.

Gent, P.R., and Coauthors, 2006, Ocean Chlorofluorocarbon and Heat Uptake during the Twentieth Century in the CCSM3, J. Climate, 19, 2366-2381.

Gent, P.R., McWilliams, J.C., 1990, Isopycnal mixing in ocean circulation models, J. Phys. Oceanogr., 20, 150-155.

Gille, S.T., 2002, Warming of the Southern Ocean Since the 1950s, Science, 295, 1275-1277.

Gregory, J.M., 2000, Vertical heat transport in the ocean and their effect on time-dependent climate change, Climate Dyn., 16, 501-515.

Hall, A., 2004, The Role of Surface Albedo Feedback in Climate, J. Climate, 13, 1550-1568.

Holland, M.M., Bitz, C.M., Hunke, E.C., Lipscomb, W.H., Schramm, J.L., 2006, Influence of the 
Sea Ice Thickness Distribution on Polar Climate in CCSM3, J. Climate, 19, 2398-2414.

Holland, M.M., Raphael, M.N., 2006, Twentieth century simulation of the southern hemisphere climate in coupled models. Part II: sea ice conditions and variability, Climate Dyn., 26, 229-245.

Huang, B., Stone, P.H., Sokolov, A.P., Kamenkovich, I.V., 2003, The Deep-Ocean Heat Uptake in Transient Climate Change, J. Climate, 16, 1352-1363.

Intergovernmental Panel on Climate Change (IPCC) Fourth Assessment Report Working Group I: The Physical Science Basis of Climate Change, 2007, http://ipcc-wg1.ucar.edu/wg1/wg1report.html

Johnson, G.C., Purkey, S.G., Bullister, J.L., 2008, Warming and Freshening in the Abyssal Southeastern Indian Ocean, J. Climate, 21, pp.5351-5363.

Levitus, S., Antonov, J., Boyer, T., 2005, Warming of the World Ocean, 1955-2003, Geophys. Res. Lett., 32, L02604, doi:10.1029/2004GL021592.

Liu, J., Curry, J.A., 2010, Accelerated warming of the Southern Ocean and its impacts on the hydrological cycle and sea ice, PNAS, 107, 14987-14992.

Meehl, G.A., and Coauthors, 2006, Climate Change Projections for the Twenty-First Century 
and Climate Change Commitment in the CCSM3, J. Climate, 19, 2597-2616.

Russell, J.L., Dixon, K.W., Gnanadesikan, A., Stouffer, R.J., Toggweiler, J.R., 2006, The Southern Hemisphere Westerlies in a Warming World: Propping Open the Door to the Deep Ocean, J. Climate, 19, 6382-6390.

Sexton, D.M.H., 2001, The effect of stratospheric ozone depletion on the phase of the Antarctic Oscillation, Geophys. Res. Lett., 28, 3697-3700.

Soden, B., Held, I., 2006, Robust Response of the Hydrological Cycle to Global Warming, J. Climate, 19, 5686-5699.

Speer, K., Tziperman, E., 1992, Rates of Water Mass Formation in the North-Atlantic Ocean, J. Phys. Oceanogr., 22, 93-104.

Steig, E.J., Schneider, D.P., Rutherford, S.D., Mann, M.E., Comiso, J.C., Shindell, D.T., 2009, Warming of the Antarctic ice-sheet surface since the 1957 International Geophysical Year, Nature, 457, 459-462.

Thompson, W.J., Solomon, S., 2002, Interpretation of Recent Southern Hemisphere Climate Change, Science, 296, 895-899. 
Thompson, W.J., Baldwin, M.P., Solomon, S., 2005, Stratosphere-Troposphere Coupling in the Southern Hemisphere, J. Atmos. Sci., 62, 708-715. 

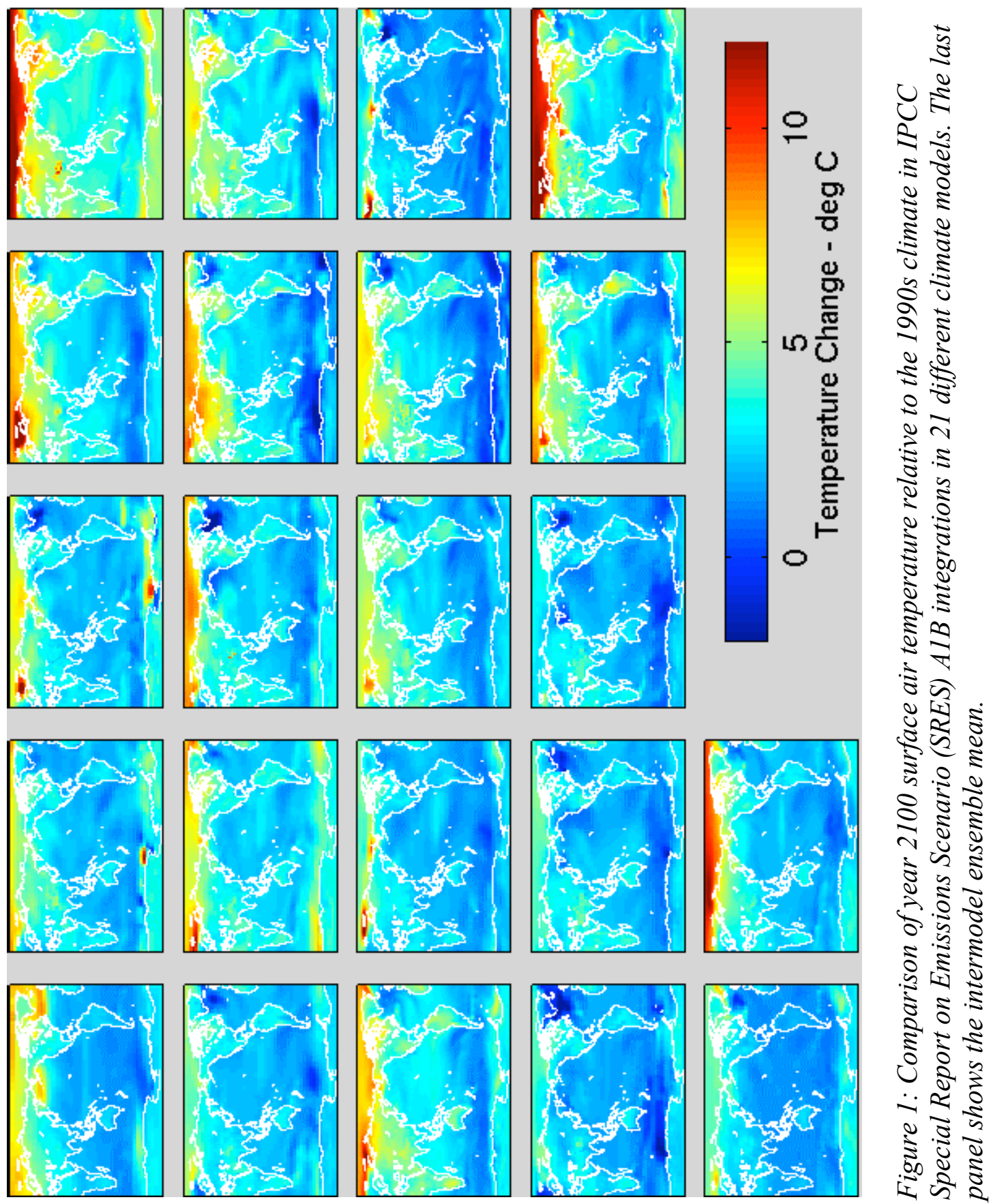

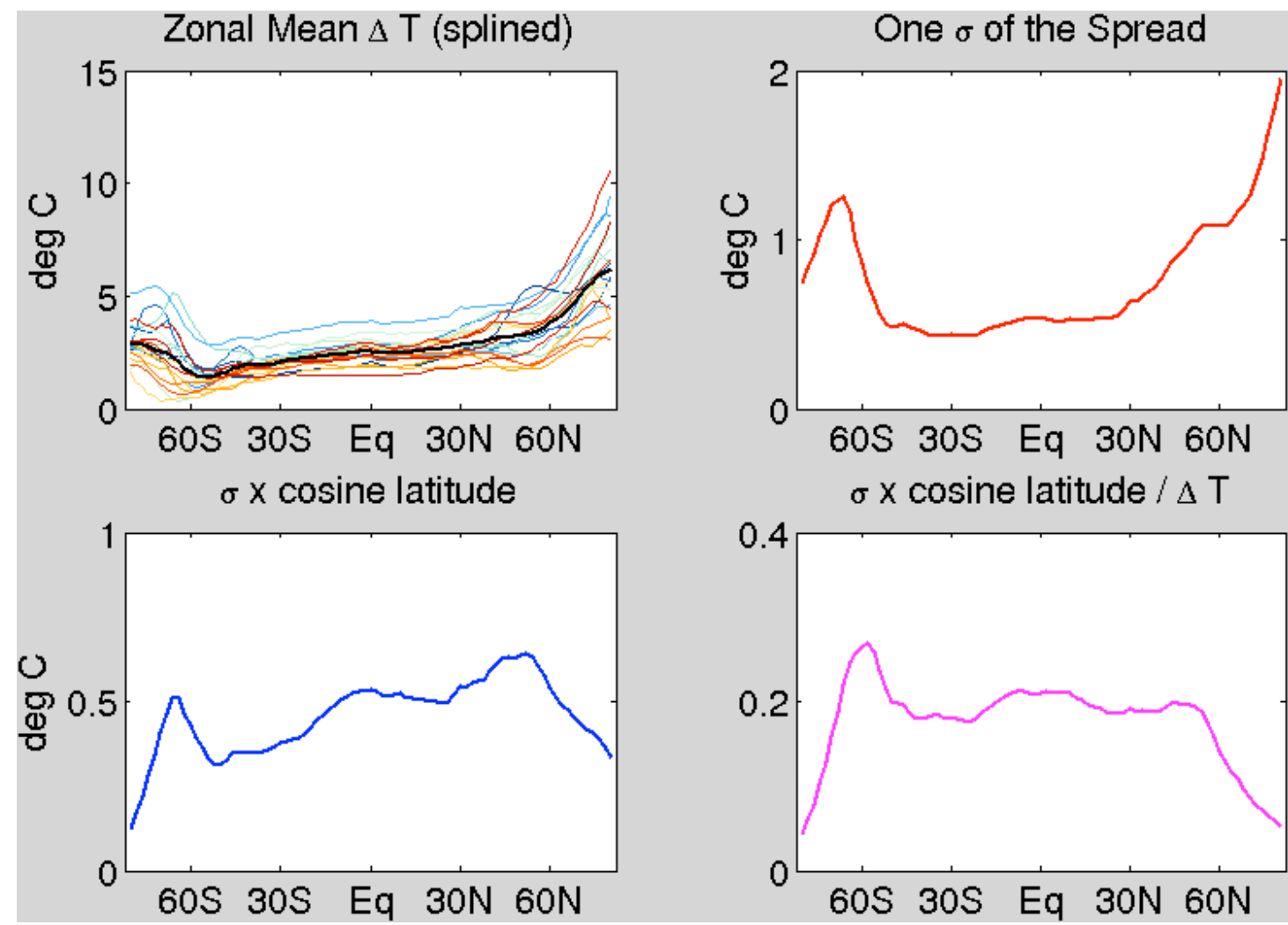

Figure 2: Zonal mean surface air temperature change of each model in figure 1 and intermodel ensemble mean (black) (upper left). Standard deviation of model results (upper right). Standard deviation scaled by area per latitude band (lower left). Previous result scaled by degree of warming per latitude, with higher values indicating greater "Areal uncertainty per degree" (lower right). 


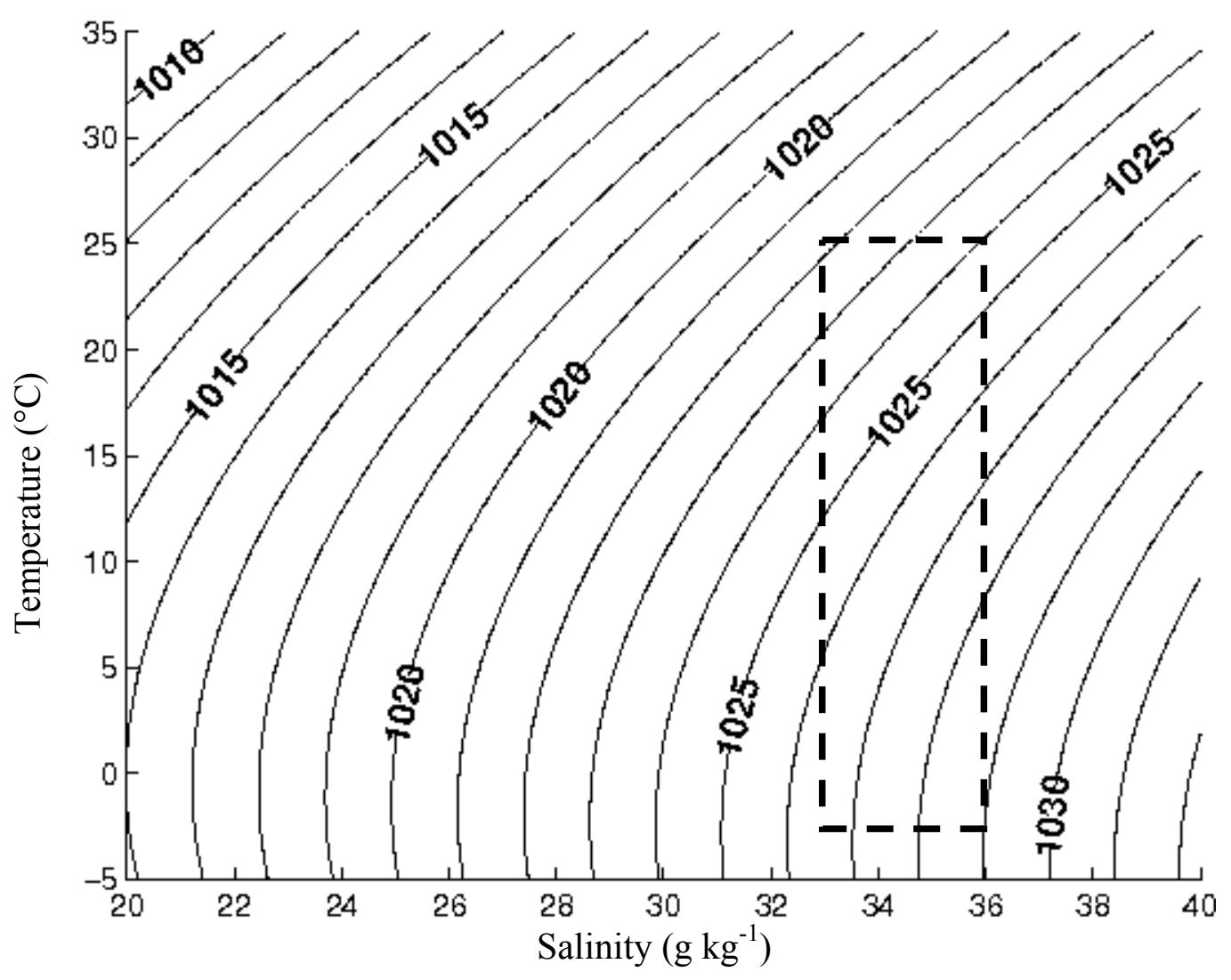

Figure 3: Equation of state of seawater $\left(\mathrm{kg} \mathrm{m}^{-3}\right)$. The box contains the approximate range of Southern Ocean surface water (to $\left.30^{\circ} \mathrm{S}\right)$. Waters near Antarctica occupy the lower end of the box. 

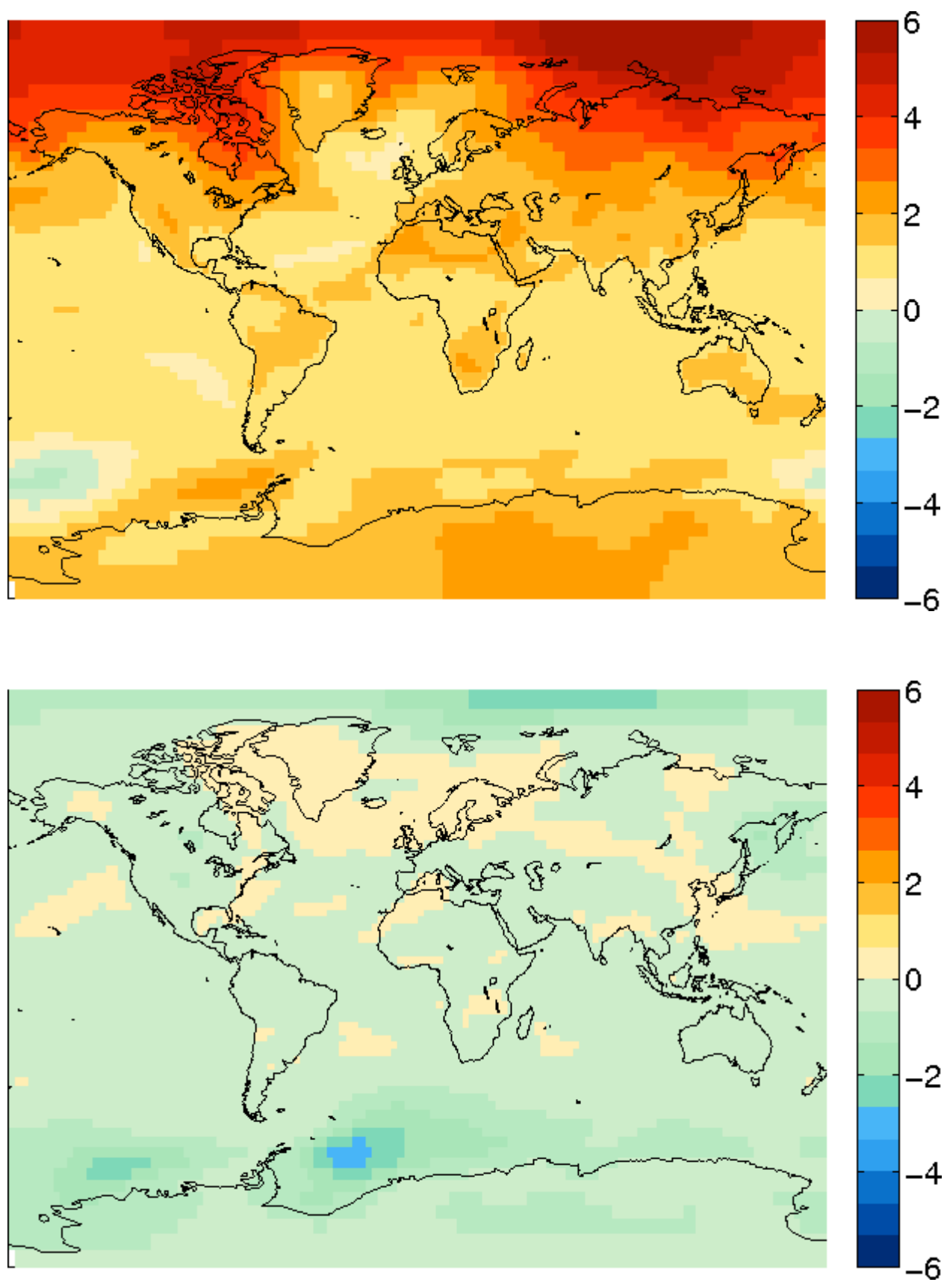

Figure 4: Annual mean surface air temperature differences (K): co2ramp - control (top) and co2ramp - climoFW (bottom), years 60-79. 

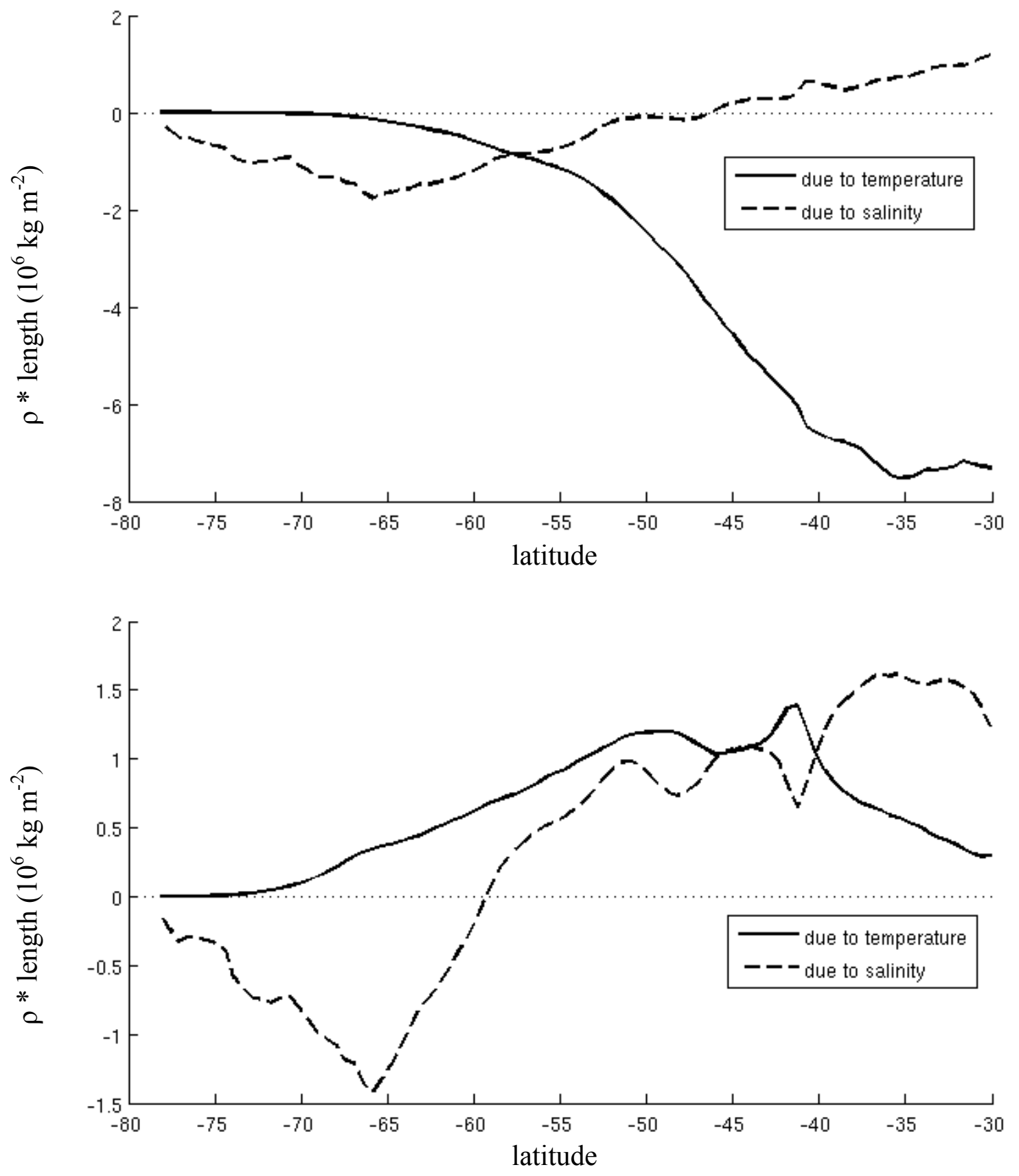

Figure 5: Surface density differences $\left(10^{6} \mathrm{~kg} \mathrm{~m}^{-2}\right)$ : co2ramp - control (top) and co2ramp climoFW (bottom), years 60-79. Density is scaled by the zonal width of the ocean at each latitude. 


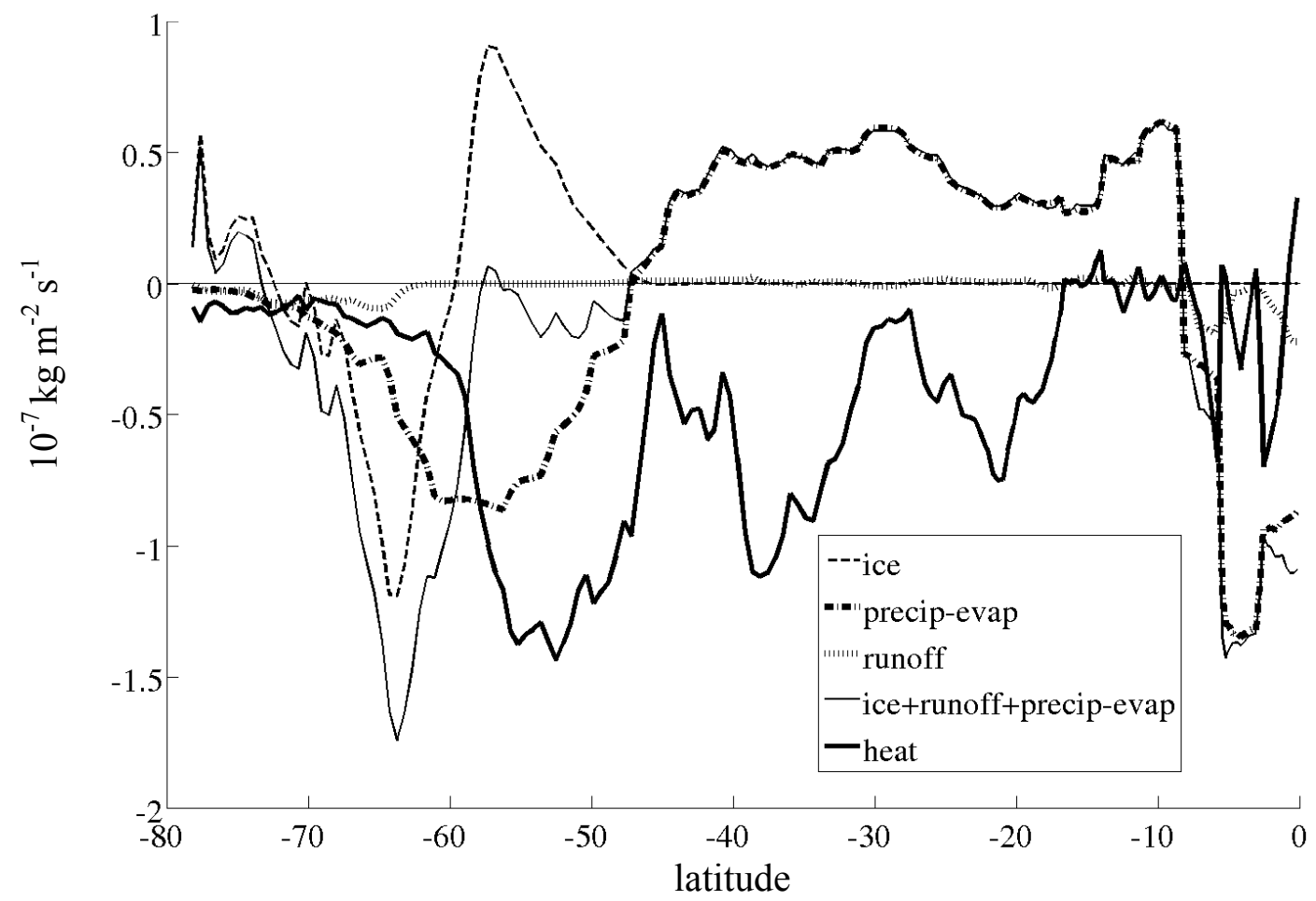

Figure 6: Anomalous surface density flux due to change in freshwater and heat input into the ocean $\left(10^{-7} \mathrm{~kg} \mathrm{~m}^{-2} \mathrm{~s}^{-1}\right)$ : co2ramp - control, years 60-79. Changes in sea ice FW flux, precipitation, evaporation, runoff, and surface heat flux to the atmosphere are considered. Values are scaled by the ocean fraction at each latitude. 

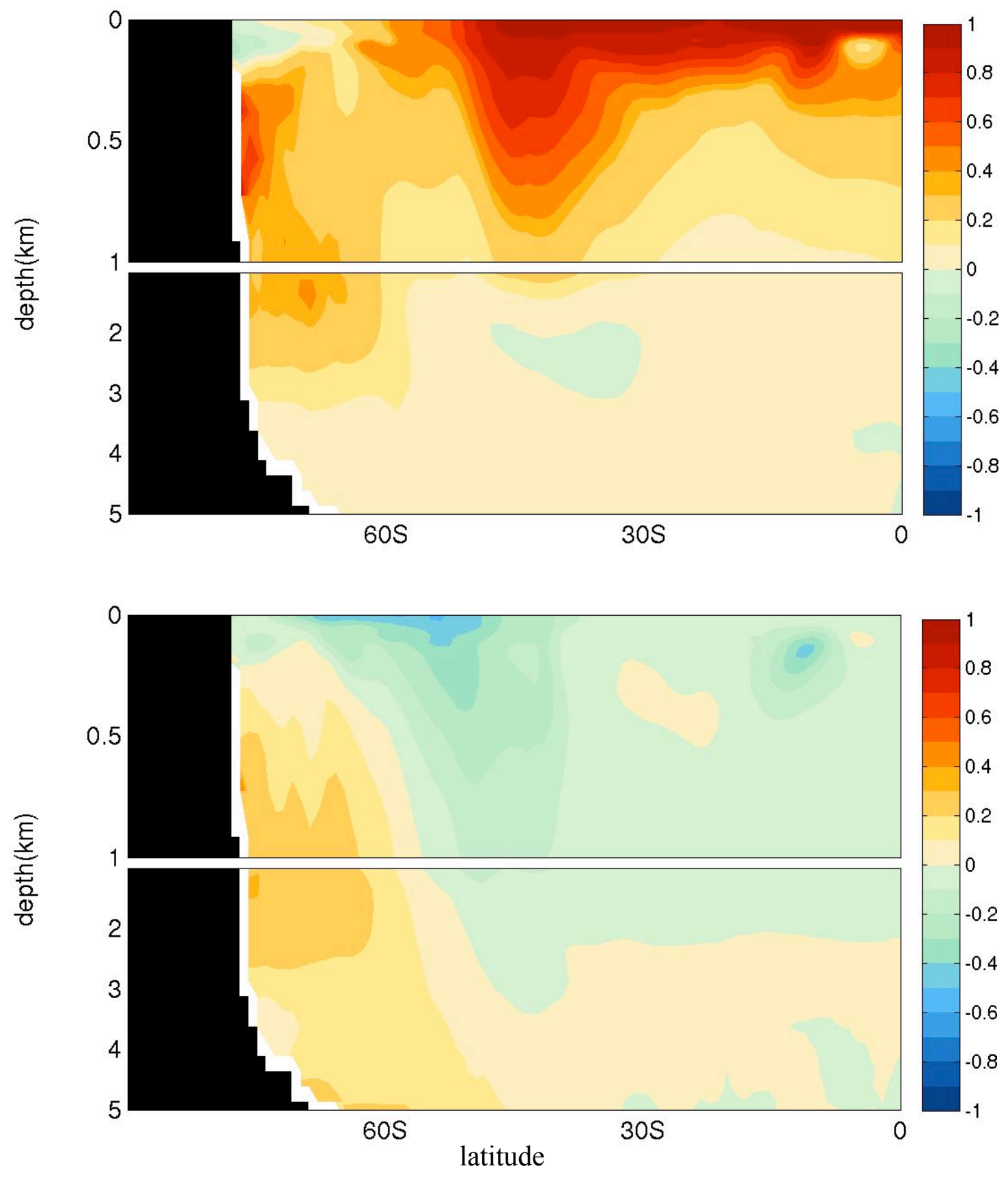

Figure 7: Difference in zonal mean potential temperature (K): co2ramp-control (top) and co2ramp-climoFW (bottom), years 60-79. 

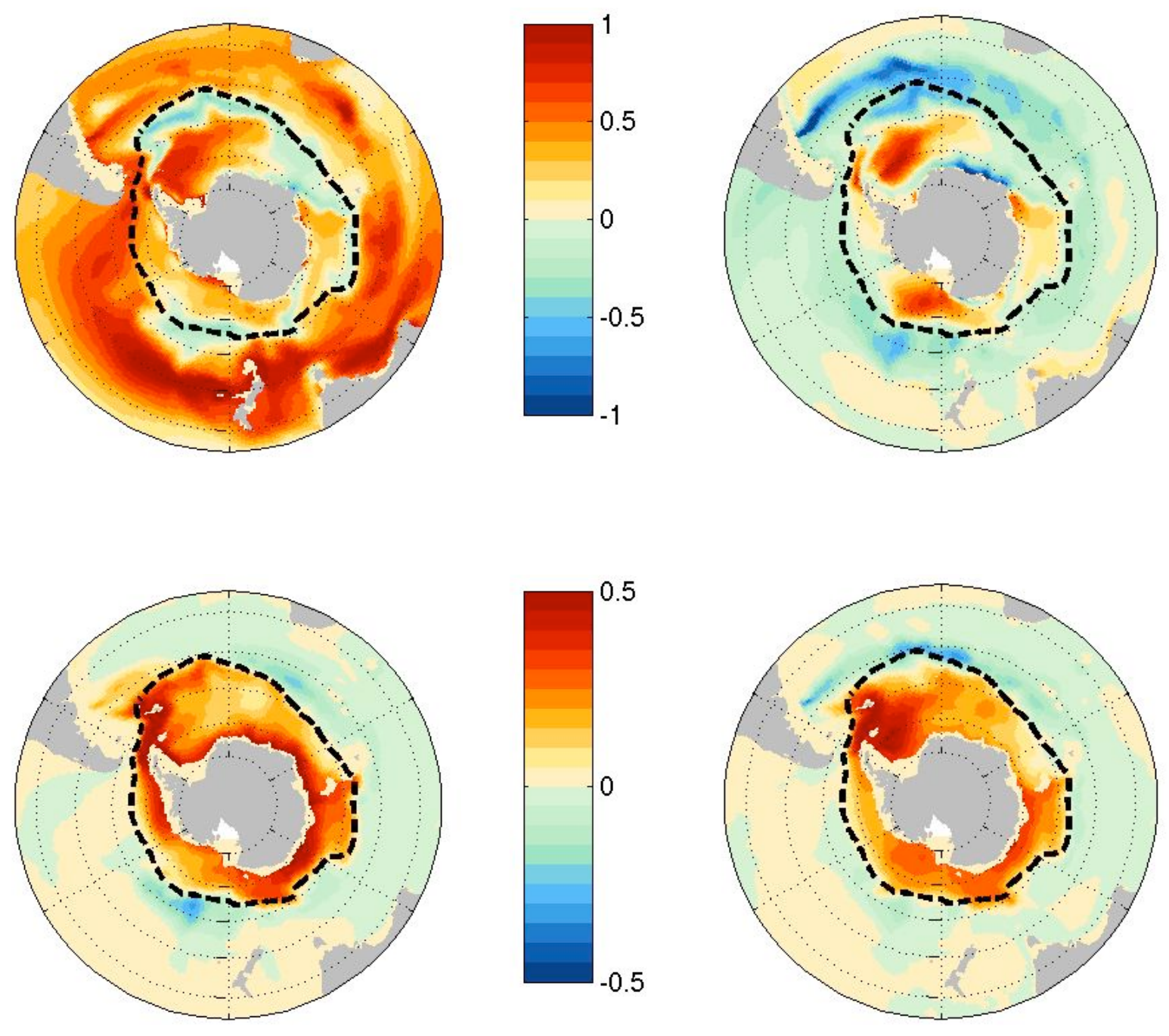

Figure 8: Difference in potential temperature (K): co2ramp - control (left) and co2ramp - climoFW (right), at depth $579 \mathrm{~m}$ (top) and $2125 \mathrm{~m}$ (bottom), years 60-79. Dashed black line is the mean 15\% sea ice cover extent in September in the 1990s climate (control). 

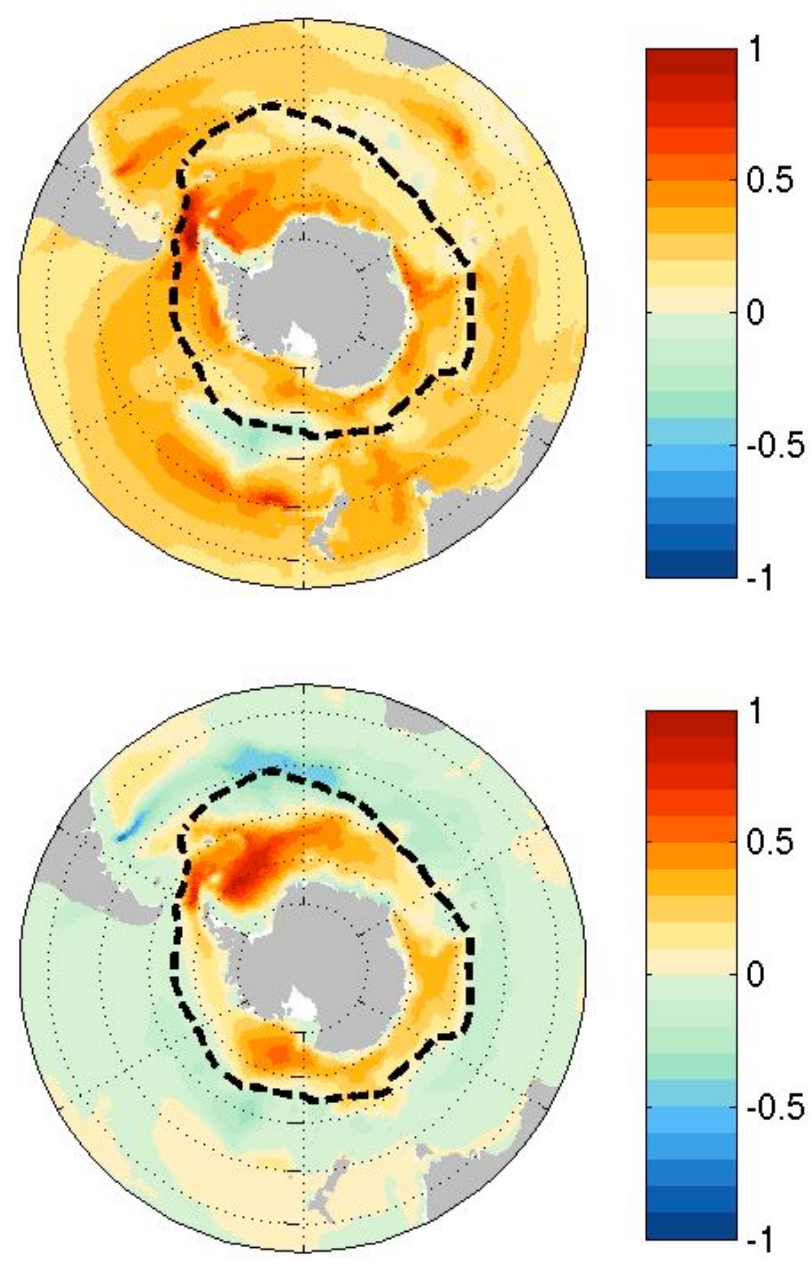

Figure 9: Difference in vertically integrated heat content $\left(10^{6} \mathrm{~J} \mathrm{~m}^{-2}\right)$ :

co2ramp - control (top) and co2ramp - climoFW (bottom), years 60-79. Dashed black line is the mean 15\% sea ice cover extent in September in the 1990s climate (control). 


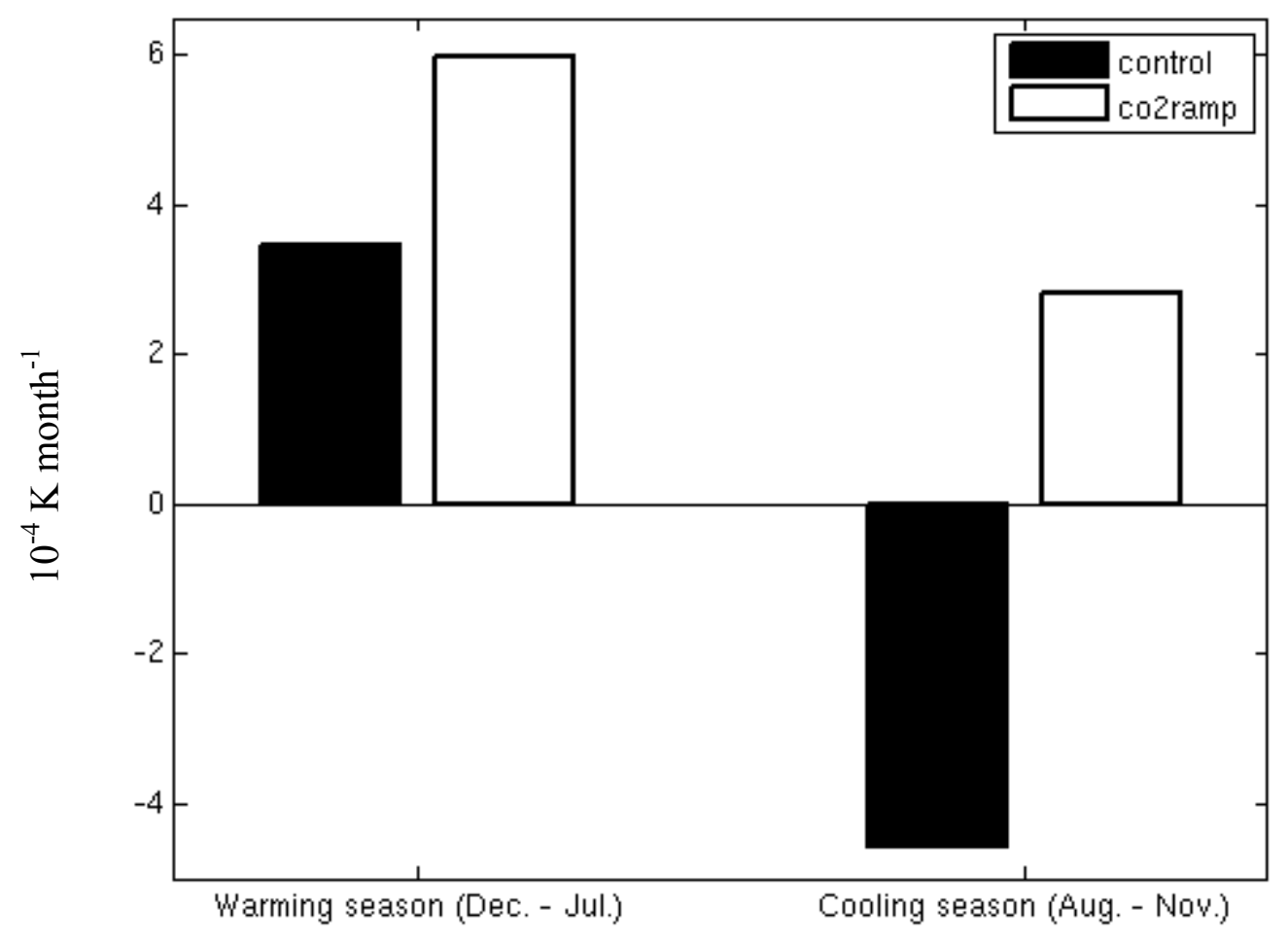

Figure 10: Heating rate $\left(10^{-4} \mathrm{~K}_{\mathrm{month}^{-1}}\right)$ in the core of the deep warming mode near Antarctica $\left(90^{\circ} \mathrm{S}\right.$ to $60^{\circ} \mathrm{S}$ and $500 \mathrm{~m}$ to $2500 \mathrm{~m}$ depth), years 60-79 (for co2ramp). 


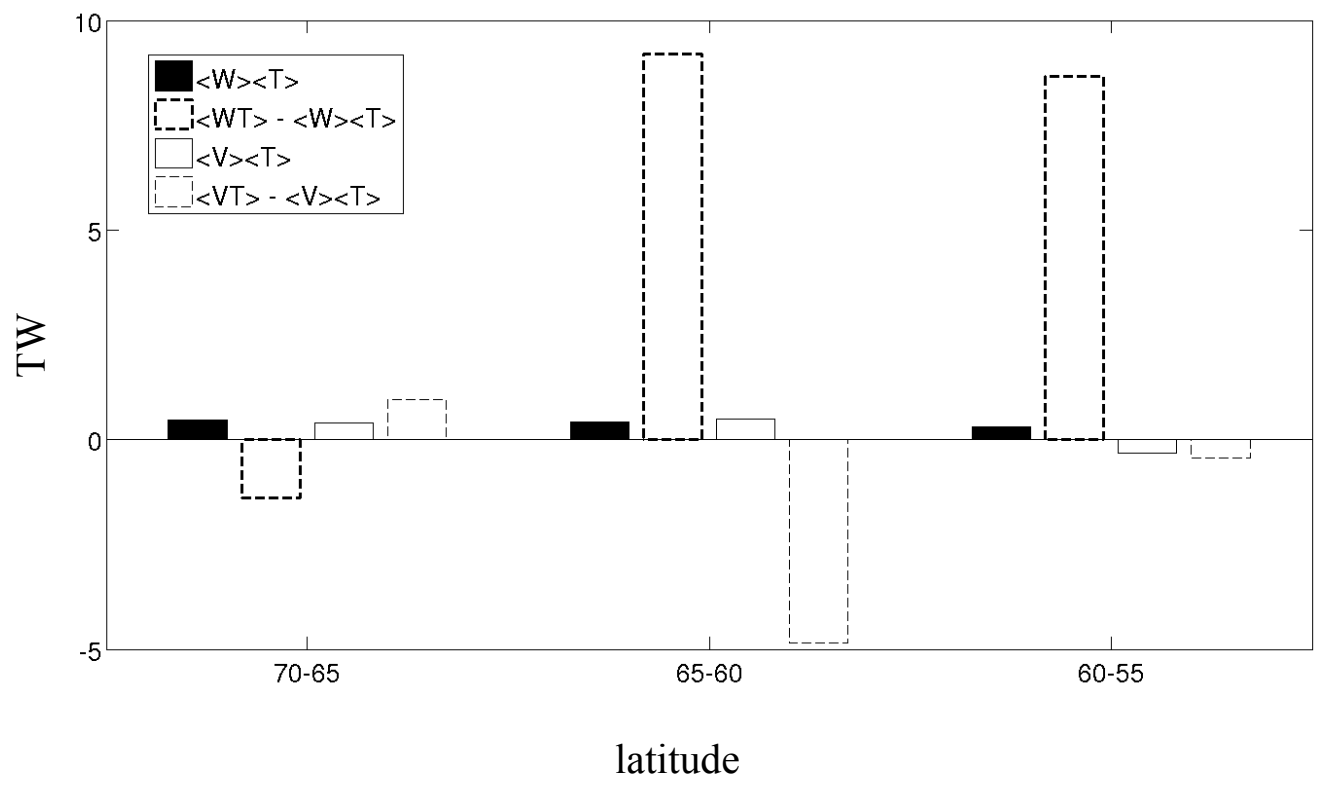

Figure 11: Ocean heat flux convergence anomalies (TW) below 1000m depth by latitude band: co2ramp-control. Solid edged boxes denote the flux convergence by the mean temperature and the mean flow, dashed boxes denote all other processes (temporal and spatial 'eddies'), dark edged boxes denote convergence due to vertical heat fluxes across the $1,000 m$ depth 'lid', and light edged boxes denote meridional heat flux convergence. Brackets indicate the mean of years 0-79. 

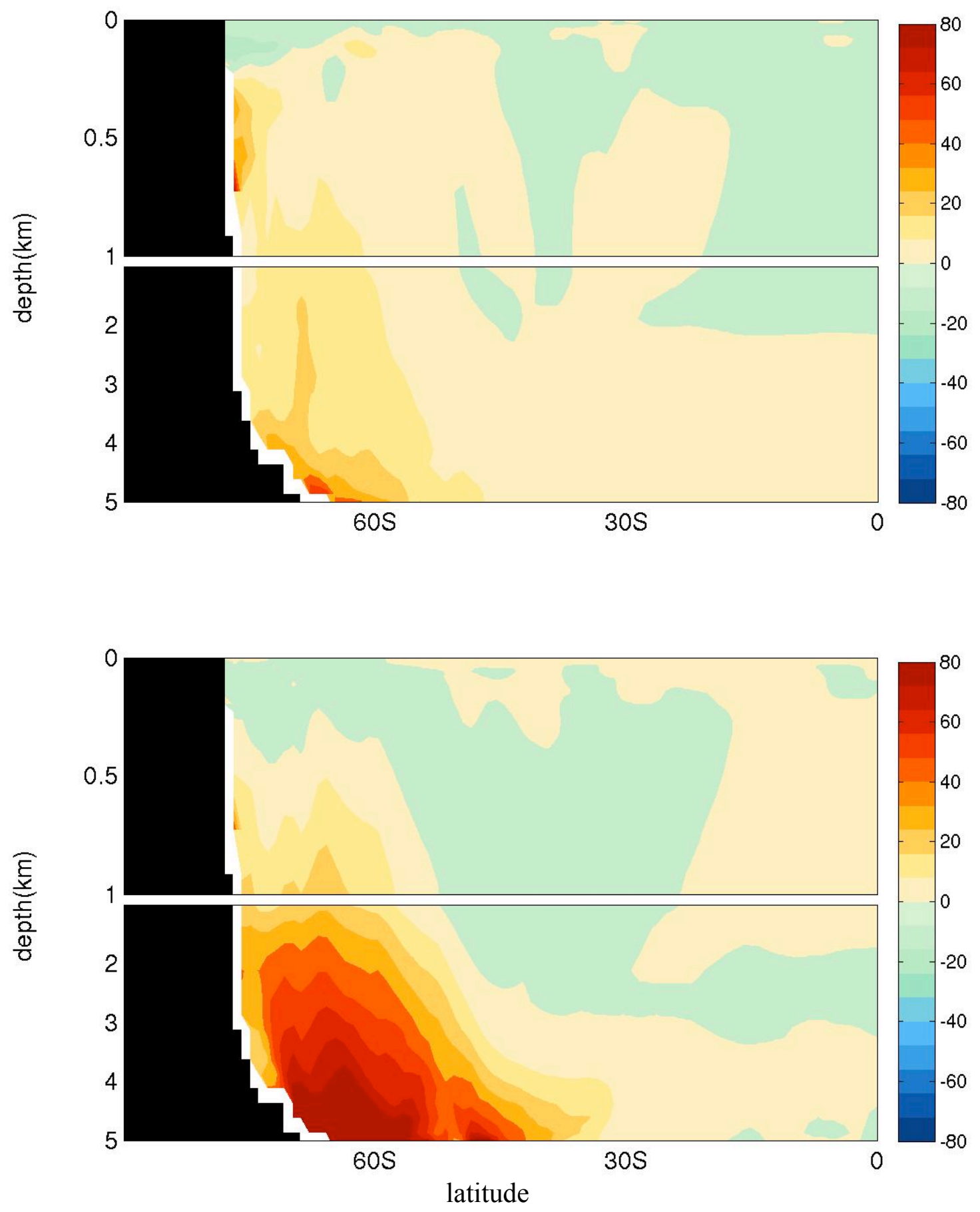

Figure 12: Difference in zonal mean ideal age (years): co2ramp - control (top) and co2ramp - climoFW (bottom), years 60-79. 

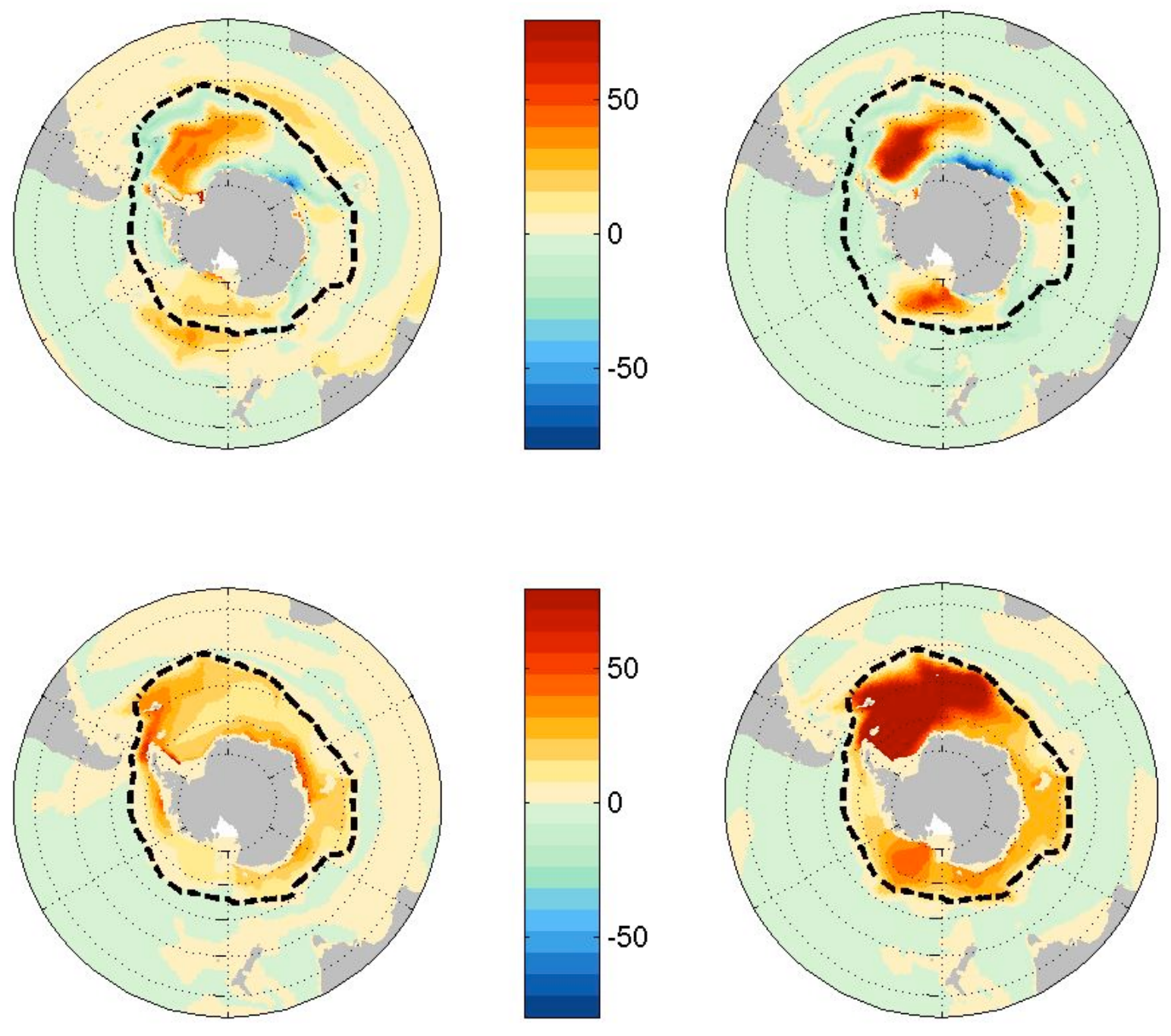

Figure 13: Difference in ideal age (years): co2ramp - control (left) and co2ramp climoFW (right), at depth $579 m$ (top) and 2125m (bottom), years 60-79. Dashed black line is the mean 15\% sea ice cover extent in September in the 1990s climate (control). 


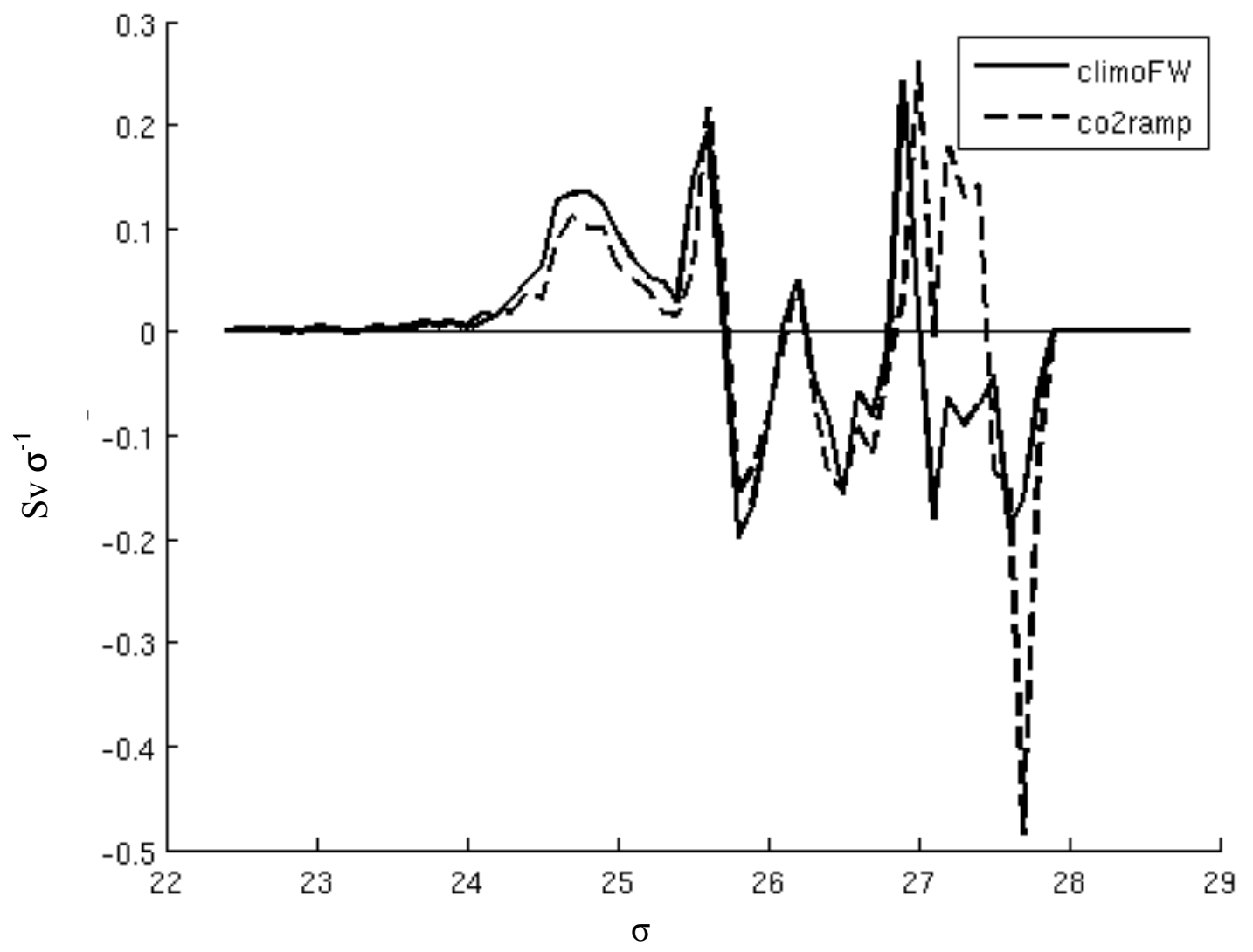

Figure 14: Change in water mass volume $\left(S v \sigma^{-1}\right)$ from control to climoFW (solid) and control to co2ramp (dashed) for the top $104 \mathrm{~m}$ of the Southern Ocean south of $30^{\circ} \mathrm{S}$. Rate is calculated from the beginning of the experiments through year 79. 


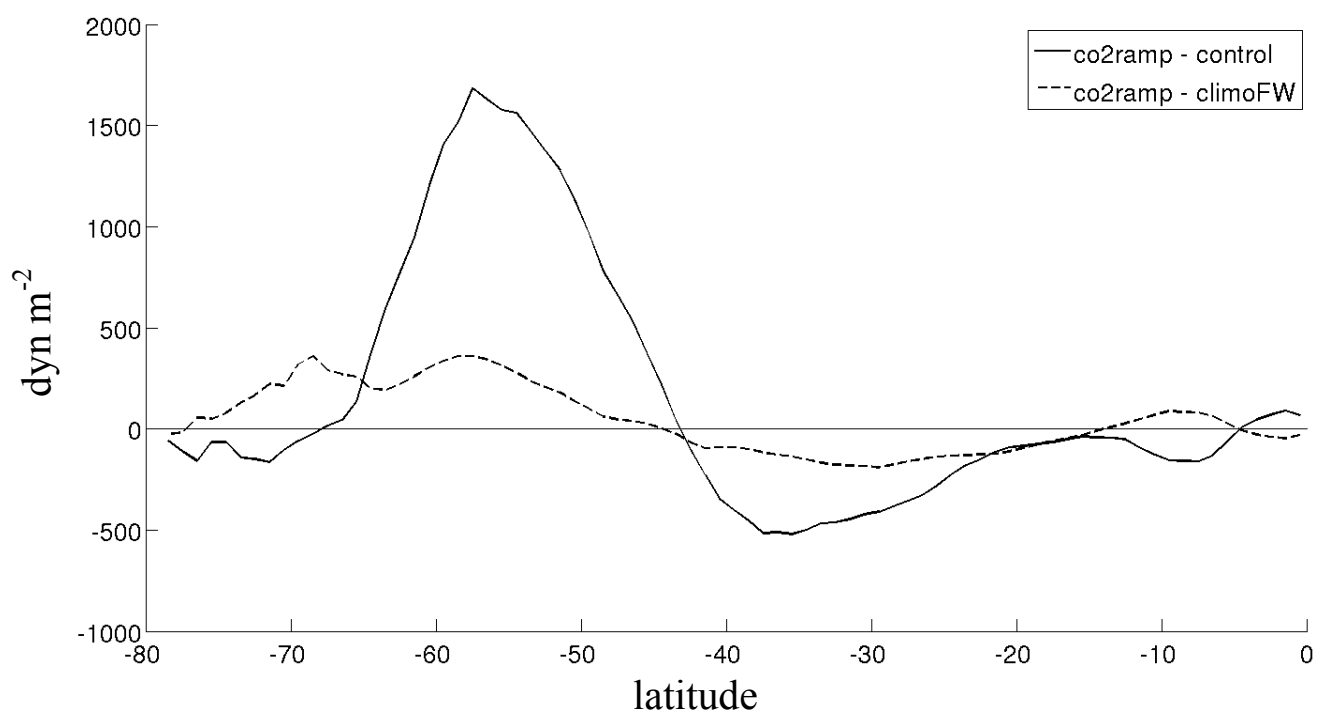

Figure 15: Wind stress anomalies (dyn $\left.\mathrm{m}^{-2}\right)$, years 60-79. 


\section{Figure Caption List}

Figure 1: Comparison of year 2100 surface air temperature relative to the 1990 s climate in IPCC Special Report on Emissions Scenario (SRES) A1B integrations in 21 different climate models. The last panel shows the intermodel ensemble mean.

Figure 2: Zonal mean surface air temperature change of each model in figure 1 and intermodel ensemble mean (black) (upper left). Standard deviation of model results (upper right). Standard deviation scaled by area per latitude band (lower left). Previous result scaled by degree of warming per latitude, with higher values indicating greater "Areal uncertainty per degree" (lower right).

Figure 3: Equation of state of seawater $\left(\mathrm{kg} \mathrm{m}^{-3}\right)$. The box contains the approximate range of Southern Ocean surface water (to $\left.30^{\circ} \mathrm{S}\right)$. Waters near Antarctica occupy the lower end of the box.

Figure 4: Annual mean surface air temperature differences (K): co2ramp-control (top) and co2ramp-climoFW (bottom), years 60-79. 
Figure 5: Surface density differences $\left(10^{6} \mathrm{~kg} \mathrm{~m}^{-2}\right)$ : co2ramp - control (top) and co2rampclimoFW (bottom), years 60-79. Density is scaled by the zonal width of the ocean at each latitude.

Figure 6: Anomalous surface density flux due to change in freshwater and heat input into the ocean $\left(10^{-7} \mathrm{~kg} \mathrm{~m}^{-2} \mathrm{~s}^{-1}\right)$ : co2ramp - control, years 60-79. Changes in sea ice FW flux, precipitation, evaporation, runoff, and surface heat flux to the atmosphere are considered. Values are scaled by the ocean fraction at each latitude.

Figure 7: Difference in zonal mean potential temperature (K): co2ramp-control (top) and co2ramp-climoFW (bottom), years 60-79.

Figure 8: Difference in potential temperature (K): co2ramp - control (left) and co2ramp climoFW (right), at depth $579 m$ (top) and $2125 m$ (bottom), years 60-79. Dashed black line is the mean 15\% sea ice cover extent in September in the 1990s climate (control).

Figure 9: Difference in vertically integrated heat content $\left(10^{6} \mathrm{~J} \mathrm{~m}^{-2}\right)$ : co2ramp - control (top) and co2ramp-climoFW (bottom), years 60-79. Dashed black line is the mean 15\% sea ice cover extent in September in the 1990s climate (control). 
Figure 10: Heating rate $\left(10^{-4} \mathrm{~K}^{\left.\mathrm{month}^{-1}\right)}\right.$ in the core of the deep warming mode near Antarctica $\left(90^{\circ} \mathrm{S}\right.$ to $60^{\circ} \mathrm{S}$ and $500 \mathrm{~m}$ to $2500 \mathrm{~m}$ depth), years 60-79 (for co2ramp).

Figure 11: Ocean heat flux convergence anomalies (TW) below 1000m depth by latitude band: co2ramp-control. Solid edged boxes denote the flux convergence by the mean temperature and the mean flow, dashed boxes denote all other processes (temporal and spatial 'eddies'), dark edged boxes denote convergence due to vertical heat fluxes across the 1,000m depth 'lid', and light edged boxes denote meridional heat flux convergence. Brackets indicate the mean of years $0-79$.

Figure 12: Difference in zonal mean ideal age (years): co2ramp - control (top) and co2ramp climoFW (bottom), years 60-79.

Figure 13: Difference in ideal age (years): co2ramp - control (left) and co2ramp - climoFW (right), at depth $579 m$ (top) and $2125 m$ (bottom), years 60-79. Dashed black line is the mean 15\% sea ice cover extent in September in the 1990s climate (control).

Figure 14: Change in water mass volume $\left(S v \sigma^{-1}\right)$ from control to climoFW (solid) and control to co2ramp (dashed) for the top $104 \mathrm{~m}$ of the Southern Ocean south of $30^{\circ} \mathrm{S}$. Rate is calculated from the beginning of the experiments through year 79. 
Figure 15: Wind stress anomalies $\left(\right.$ dyn $\left.\mathrm{m}^{-2}\right)$, years 60-79. 